\title{
EDITORIAL
}

\section{Science in Canada and the Maritime Region - Nurturing A Brighter Future}

With the change in federal government in Ottawa in October, 2015, a heavy weight has been removed from its public service, employees and programs. One could almost hear the collective sigh of relief, certainly evident at the Canadian Science Policy Conference held shortly afterwards in Ottawa. Does this change in government and its pronouncements on science and evidence based policy beckon a brighter future for public, university and private sector science in Canada? If so, what are some of the science priorities for this region? These questions and others are addressed here to stimulate a discussion within NSIS and the Nova Scotia science community.

As public service science recovers, major challenges are facing us. Whole programs and important committees and advisory groups, with scarce skilled personnel, need to be resurrected. Rebuilding the civil service, i.e. hiring lots more civil servants, is never a popular activity for any government; it does not garner much popularity with the public or many votes at the next election. Furthermore, the significantly reduced, core (i.e., most important) departments and agencies, without essential programs, become the "new normal". Memories fade about what was once in place. This is a form of "knowledge extinction', eloquently discussed by author, J. B. MacKinnon, in his recent book, The Once and Future World. (MacKinnon 2014) However, with public input and guidance from all concerned quarters (NGOs such as NSIS, the Public Service Alliance of Canada, the universities and various specialized research institutes, enlightened citizens, and others), policies can be (re)established to guide the rejuvenation of essential science programs. This is critical to the public good, and to Canada's economic, social, environmental and cultural future.

One of these programs, closed down despite contributing to the health and sustainability of Maritime marine resources (i.e.fisheries), was the environmental chemistry and toxicology research program of Fisheries and Oceans Canada (DFO). Formerly, a number of research units were in place across the country that conducted applied studies on various water pollution topics/issues of priority, e.g., oil pollution, pesticides, 
endocrine disrupting chemicals, contaminants in fish tissues, ocean acidification, chemical effects in marine mammals, and others. This research was and is fundamental to the protection of fishery resource species and aquatic ecosystems across Canada, from east to west, north to Arctic seas, and south to the Great Lakes. The research work supported the policies and legislation of DFO, as well as that of other departments with responsibilities for the health of aquatic ecosystems, habitats and species, e.g. Environment Canada (EC, now Environment and Climate Change), Natural Resources Canada, and Health Canada. This type of science is particularly important to North West Atlantic waters, faced with the prospect of warmer and more acidic conditions, the risk of nearshore oil spills and blowouts in the offshore, exposure to toxic chemicals from land-based sources and shipping accidents, and other threats. Some of these threats are addressed in recent DFO ecosystem status reports and in studies contracted under the HOTO (Health of the Oceans) initiative of DFO and EC. They clearly showed the need for the underlying science.

But not all is lost. To the federal governments' credit, they have appointed young Ministers to the portfolios of Innovation, Science and Economic Development (ISED), Environment and Climate Change, and DFO. The Minister of ISED recently announced six new research chairs for NS universities (The Chronicle Herald 2016a) with a total of 21 new and renewed Atlantic Canadian research chairs in total, all good signs of a new approach and recognition for regional science. Most recently, new operational monies have been allocated to DFO; one hopes some of it will be used to resurrect the lost aquatic environmental programs.

Given the change in attitude and policies of the new federal government regarding science, and their clear statement in support of evidence-based policies (see the Canadian Science Policy Conference, Nov. 2015), what are the opportunities for advancing core science and science support in the Maritimes, and in Nova Scotia in particular? What topics especially require support? Support and innovation is required not only for our public service but for all sectors. Why is this so important to our region? What do we lose if such support, intellectual engagement, new and innovative ideas, and new and renewed programs are not forthcoming? How do these questions relate to keeping our young people in our Region? Why should Atlantic citizens care? There are many such questions, all requiring thoughtful debate 
and informed answers. They should be discussed and debated within the NSIS and other provincial bodies.

The Governor-General of Canada, David Johnston, recently pointed out that Canada has a culture of research excellence, with many recipients of international awards, prizes and other types of recognition (Johnston 2016). This was underlined recently by the 2015 Nobel Prize for Physics awarded jointly to Dr. Arthur McDonald (Canada) and Dr. Takaaki Kajita (Japan) for their research leadership and discoveries about solar neutrinos and nuclear reactions in the sun. Dr. Arthur McDonald is a Nova Scotian by background and education, bringing great honor to his home province, as did Willard Boyle, born in Amherst and also a physics Noble laureate, awarded in 2009. Johnston stated in his uplifting article: "Together, in every sphere of activity, let's build on our momentum and make sure the world acknowledges and celebrates the truly stellar achievements of Canadian trailblazers". These two men were trailblazers, indeed!

Although risking the un-intentioned exclusion of many hard working and productive persons and their achievements, some other, recent Nova Scotian science trailblazers must be mentioned. The National Research Council, Halifax Laboratory's biotoxin metrology group continues to makes fundamental advancements identifying new algal toxins with highly sensitive chemical techniques, hence contributing to the health safety of shellfish products from the Atlantic fishery (Quilliam 2016). Last year, Dr. Axel Becke of the Chemistry Department, Dalhousie, won the distinguished NRC Herzberg Medal for achievements in the field of computational chemistry. And the young are contributing too - the 13 year old Rachel Brouwer of Bedford, NS, won a gold medal in a Canada-Wide Science Fair for "a new, life-saving, water pasteurization unit, made of inexpensive and accessible materials, and designed for people in developing countries" (The Chronicle Herald 2016b). Each year, the NSIS receives marvelous scientific papers written by young scientists as part of a Nova Scotia science writing competition. However, once through graduate school, many newly trained $\mathrm{PhDs}$ go for long periods of time without appropriate employment, a loss to our research oriented community and a problem that should be resolved quickly in order that our region may stay competitive and attractive for such young researchers (Thorpe 2015).

Amongst others in the region, Dalhousie University is a leader in ocean research through its Ocean Tracking Network and MEOPAR, 
both programs so important in this era of climate change and overexploitation of fisheries resources. There are many other associated research programs in biology, oceanography, and marine affairs. A long association with the Bedford Institute of Oceanography is a vital and promising link, but only if Canada from coast to coast can renew its aging research fleet and restore its government research staff (Pickrill 2015). There is also new research on the use and influence of marine environmental and fisheries information, through the Environmental Information: Use and Influence (EIUI) program (see www.eiui.ca), gaining new insights into the science-information-policy interface in ocean management (MacDonald et al. 2016). Acadia University in Wolfville continues to conduct original and innovative research on the potential impact (or not) of in-stream, tidal power generating units on the Bay of Fundy environment, its living resources and wildlife. Cutting edge ecotoxicological research on persistent organic pollutants is conducted at the University of New Brunswick (UNB) - Saint John campus, and fundamental ecological research is conducted at Mt. Allison University and UNB-Fredericton. Many other examples exist across a wide spectrum of scientific fields, and the research is published widely, including at times in the pages of these Proceedings (PNSIS). Hopefully, the PNSIS will reflect a sample of this new work over the next few years.

Especially pertinent to Maritime Canada is the continued work of the Council of Canadian Academies, focussed on "science advice in the public interest", most recently with expert panel reports on Canadian ocean science (CCA 2013) and the Alberta oil sands (CCA 2015). As mentioned earlier, the recent statements of support for science of the new government were given at the CSPC in Ottawa; the new Minister of Science gave a rousing and well-received speech to delegates, promising new funding and collaboration.

To summarize, how can the NSIS contribute to this new period of science support for Canada and the Maritime Provinces? What do members think about this opportunity? Should we become more active in producing consensus documents on regionally important and sometimes controversial science-based topics in the public sphere, analyses that could assist policy and decision making (CCA 2013, 2015, Leach and Rennie 2015, MacDonald et al. 2016)? What sorts of themes and topics should NSIS have for its well-attended, annual lecture series? What else should the Society do, to supplement the 
program of lecture series, science essay contest and funding of science fairs, to encourage young people to choose a career in science, and especially to stay in this region for professional positions in industry, academia government and non-government organizations, hence contributing to the region's economy and future?

For Nova Scotia and the Maritimes to thrive in the 21st century, in a highly competitive world, we should be communicating to the public, media and politicians on issues of the day, problems that require scientific enquiry and advice, and be encouraging new ideas and approaches to regional science. NSIS may have a role here but what it does is decided by its Council, Members, and our interested public. Perhaps a special meeting or round table discussion with Members would help set some new policy directions and goals for NSIS. Your ideas and contribution are needed in this new period of Canadian science support and communication, to ensure the wellbeing of our citizens, care for the environment and a brighter future for science across the Maritime region.

\section{REFERENCES}

Council of Canadian Academies (CCA). (2013). Ocean Science in Canada: Meeting the Challenge, Seizing the Opportunity. The Expert Panel on Canadian Ocean Science. The Council of Canadian Academies. Ottawa, ON. 165 p.

Council of Canadian Academies (CCA). (2015). Technological Prospects for Reducing the Environmental Footprint of Canadian Oil Sands. Ottawa, ON. 252 p.

Johnston, D. (2016). Science. Canada's culture of research excellence. The Globe and Mail, February 10th, 2016. Opinion piece.

Leach, A. \& Rennie, M. (2015). Public servants. Scientists should speak freely - sometimes. The Globe and Mail May 22nd , 2015. A11.

MacDonald, B.H., Soomai, S.S., De Santo, E.M. \& Wells, P.G. (Eds). (2016 in press). Science, Information, and Policy Interface for Effective Coastal and Ocean Management. CRC Press, Taylor and Francis Group, Boca Raton, FL.

MacKinnon, J.B. (2014). The Once and Future World. Nature As It Was, As It Is, As It Could Be. Vintage Canada, Random House, Toronto. $256 \mathrm{p}$.

Pickrill, D. (2015). Canada scuttles its ocean science capability. The Chronicle Herald, May 27th, 2015. A12.

Quilliam, M. (2016). The hunt for red tide toxins. Lecture, Bedford Institute of Oceanography, Dartmouth, NS. February 19th, 2016. (Wells, unpubl. notes). 
The Chronicle Herald. (2016a). Dal gets $\$ 5.6 \mathrm{~m}$ for research. Four other universities receive funding through federal program. The Chronicle Herald, February 10th, 2016. A5.

The Chronicle Herald. (2016b). Science that saves. N.S. teen's life-saving drinking water system inspires others. The Chronicle Herald, February 10th, 2016. A3.

Thorpe, J. (2015). But is it science? In: Facts and Arguments. The Globe and Mail, March 17th, 2015. L8.

P.G. Wells

Editor, PNSIS

February 2016 